revision in this country. There is a clear and concise exposition of the modern concepts. It embodies, too, a comprehensive and clearly outlined classification of the diseases causing a rise in the intraocular tension, their diagnosis and treatment. The final chapter is particularly interesting as it describes in some detail the organization of American glaucoma clinics and their methods of educating patients.

For those that require a comprehensive reference on Glaucoma this book can be highly recommended.

\section{EDEN AND HOLLAND'S MANUAL OF OBSTETRICS}

By Alan Brews, M.D., M.S., M.R.C.P., F.R.C.S., F.R.C.O.G. I I th edition. Pp. xxi +75 I, fully illustrated. London: J. \& A. Churchill Ltd. 1957. 63s.

The fact that within four years yet another edition of this standard text book has been called for, is itself proof of its popularity. In fact, it does cover the whole of the requirements of any candidate for any qualifying examination in obstetrics.

Furthermore, it virtually covers everything that the postgraduate needs to know about the subject for higher degrees in obstetrics. If only one could persuade postgraduate students to concentrate on a book such as this and not confuse themselves by reading unnecessary journals and papers. Here is not only crystallized the cumulation of knowledge obtained by Mr. Brews from his predecessors as editors of this text book, but also a wise and balanced summary of current obstetric practice such as can be produced only by a man as well versed in the practical aspects of his subject as in the academic.

There are minor constructive criticisms to be made.

Fig. $37 \mathrm{I}$ seems to be slightly wrongly labelled.

Some of the illustrations might well be dispensed with, especially such as the rather ugly ones on pp. (plates) I 9 and 20 where the colour process has not really been quite up to standard.

Once again, the dust jacket of J. \& A. Churchill's books calls for criticism because it is dull and uninteresting, as, indeed, is the binding of the book itself.

The text itself deserves a more presentable setting.

\section{E.E.P.}

\section{5-HYDROXYTRYPTAMINE}

Edited by G. P. Lewis, Ph.D. Pp. xvii +253 , illustrated. London: Pergamon Press Ltd. 1958. £3.

This is a report of the proceedings of a symposium organized by the Coordinating Committee for Symposia on Drug Action in London on April I and 2, 1957. The publishers and editor are to be congratulated on the speed with which the report has been published.

The subject is divided into three main headings, namely, occurrence, metabolism and actions, the latter being further subdivided into a number of sections. A verbatim report of the discussion at the end of each section is also included.

This is a most useful book, as it contains contributions from prominent workers in many countries who are actively engaged in the study of this remarkable substance. Unfortunately Dr. V. Erspamer, one of the earliest workers in the field, was unable to be present.

The complexity of the problem which 5-hydroxytryptamine (serotonin) presents, is well illustrated by the titles of the various sections devoted to its actions. These are as follows-cardiovascular; nerve endings and ganglia; carcinoids; anaphylaxis; gastric secretion. There is also a section on peripheral antagonists and one on central actions and antagonists.

One of the greatest difficulties met with in investigating serotonin is that of differentiating between pharmacological and physiological effects, and Sir Charles Harington in his opening remarks stresses the need for a solution to this problem. Although the function of serotonin in normal physiology is still not finally decided, the present volume gives most of the available evidence in a compact and easily accessible form which should be helpful to all those interested in the subject. It will undoubtedly stimulate further interest in this fascinating biochemical problem.

F.W.D.

\section{HOMOSEXUALITY, TRANSVESTISM AND CHANGE OF SEX}

By Eugene de Savitsch, M.D. Pp. viii +120.

London: William Heinemann. 1958. 12s. 6d.

The author undertook to write this book in the first place in order to satisfy medical enquiries about the 'change of sex' operation. Such an operation, however, is but one stage of an extremely complex process of maldevelopment and maladaptation, and the book, therefore, covers some of the aspects of sexuality which lead to surgery of this kind.

The early chapters consider homosexuality and transvestism, and compare social attitudes towards them. The Wolfenden Report is discussed, together with the treatment of homosexuals, including the use of sex hormones and castration. Further chapters describe in a detailed and fully illustrated way the surgical methods employed in the Leber case, which is very fully reported, and moral and legal issues. Three appendices give legal, psychiatric and surgical reports respectively.

While this subject is too comprehensive to be dealt with adequately in such a small volume, this is the best presentation of the facts which has so far 
appeared. It provides a very satisfactory statement of the legal and psychological implications of this kind of surgery, and gives a much-needed factual background for the psychiatrist and surgeon faced with these trans-sexual problems.

L.R.C.H.

\section{AN ATLAS OF FETAL AND NEONATAL HISTOLOGY}

By M. A. Valdes-Dapena, M.D. Pp. xi +200 , fully illustrated. London: Pitman Medical Publishing Co. Ltd. I 957 . 90s.

As the title implies, this is a histological atlas of the neonatal period which, as claimed in the preface, is a period of increasing importance but which has been neglected. For this reason the book will be very useful even though many of the photographs are not of the highest quality. The work is based on more than 400 cases.

D.M.P.

\section{NEUROPATHOLOGY}

By J. G. Greenfield, M.D., F.R.C.P., LL.D., W. BlackWOOD, M.B., Ch.B., F.R.C.S.E., M.R.C.P.E., W. H. MCMenemeY, M.A., D.M., F.R.C.P., A. MEYER, M.D. and R. M. Norvian, M.D., M.R.C.P., D.P.M. Pp. vi +640 , with 370 illustrations. London: Edward Arnold Ltd. 1958. I05s.

This book is a complete review of the pathology of the central and peripheral nervous systems with the exception of cerebral and spinal tumours. It contains the results of much original work as well as a comprehensive summary of the relevant literature. The standard of the various chapters is uniformly high, and it can be safely stated that there can be no subject of importance connected with the pathology of the nervous system which is not referred to.

It is difficult to pick out any particular section for special mention out of such a wealth of material. Vascular and infectious diseases of the nervous system are fully covered and there is a particularly interesting chapter on malformations of the nervous system and diseases occurring early in life. The demyelinating diseases are discussed in the light of recent knowledge and the dementias and progressive diseases of the basal ganglia are described in detail; all conditions in which the diagnosis may only be established for certain at autopsy.

This book is obviously the product of a great deal of experience in the field of neuropathology and it cannot fail to be of interest and value to any-⿳亠丷厂 one whose work is connected in any way with thisz subject. It is attractively presented, well illustrated and has an excellent bibliography attached to each chapter. It can therefore be unreservedly recom mended and there can be no doubt that it willes become an established book of reference and wilfo prove a fitting memorial to the knowledge and teaching of Dr. J. G. Greenfield.

N.S.G.

\section{AUTONOMIC DYSPRAXIA}

By Brian G. Haynes, M.B., B.S., M.R.C.P. Pp. viii + I22. London: H. K. Lewis \& Co. Ltd I 958 . I $5 \mathrm{~s}$.

The subtitle: 'An hypothesis for the mechanism. of psychosis, neurosis and psychosomatic disease $\stackrel{\omega}{\perp}$ covers rather too broadly the scope of this work, $\omega$ which has little to say about psychosis itself. Theor author defines his title as a physiopathological condition in which the disordered action of autonomic control has central subcortical origin and stems from emotional overload. Such a condition is said은 to include not only the classical forms of psycho- neurosis and the newer classifications of psychoso- $\infty$ matic medicine, but also a wide variety of " organic diseases such as rheumatic fever, diabetes mellitus, $\frac{\mathbb{D}}{7}$ coronary occlusion, appendicitis, nephritis, leukor rhoea, thyrotoxicosis and many more.

After an introduction and a chapter on nomenc ture (which is likely to meet with some criticisme; o the book then discusses the functional diseases, t symptoms and physical signs of autonomic dyspraxia, and then diagnosis, prognosis, and treatment. A summary, short bibliography, and index are provided.

The later chapters make it clear that this provoca- $\frac{\mathbb{D}}{\mathbb{D}}$ tive monograph is doing more than renaming the rose, for the author's hypothesis carries practical $\overrightarrow{0}$ implications for diagnosis and therapy that cannot 3 be lightly dismissed. Dr. Haynes has been practising what he now preaches for some ${ }_{5} 5$ years; his methods have apparently survived the test of time and remain more successful, in the author's opinion, than those of traditional thinkers. In denigrating the functional-organic dichotomy which forms a major step in so much medical diagnosis, he has gained an important victory for psychosomatic medicine, and gives many original ideas which make this a book which cannot be ignored. We may not $\stackrel{9}{9}$ all agree with his hypothesis, but having studied it, we shall all be better physicians.

\section{L.R.C.H.}

